\title{
EDUCACIÓN
}

\section{"Ave aventura": una propuesta educativa para el primer ciclo de EEB en el Museo de Historia Natural del Paraguay}

\author{
Francisco Javier Colmán Ramírez¹, Hugo Daniel Yahari
}

\section{Resumen}

Introducción: La sociedad Sudamérica ha experimentado cambios en su Diseño Curricular adaptando las capacidades desarrolladas del en el aula, se toma como eje el área de Medio Natural, ya que en la experimentación es un área cuyos contenidos son un poco olvidados a la hora de desarrollados en aula, y esto la motivación de la investigación en los niños. Considerando el contexto donde se desarrollará la propuesta didáctica cabe mencionar los Fines de la Educación paraguaya que es la búsqueda de hombres y mujeres integrales. Por ello, se analiza cuarto de los Museos latinoamericanos de relevancia que se encuentran en los siguientes países Bolivia, Perú, Uruguay y Chile, Museos que cuentan con diferentes programas educativos desde jardín hasta el bachillerato, destacándose Bolivia que cuenta con una Alianza con el Museo de Ciencias Naturales de Madrid (MNCM). De allí nace la propuesta didáctica "Ave Aventura", diseño que se pretende implementar como uno de los primeros programas educativos en el Museo, que consiste en un taller con actividades relacionadas tomando tres capacidades del programa paraguayo que están vinculadas con la colección.

Ave aventura es una propuesta dividida en dos fases:

La primera fase es un taller con los maestros denominado Volando con la Imaginación, la fase dos es la Actividad con los niños "Ave Aventura".

Objetivos: Dotar de un Programa Educativo al MHNDP, dirigido a estudiantes del 1 을 Ciclo de la EEB y Promover un mayor interés en el alumnado de 10 Ciclo EEB en la preservación y protección de especies nativas que forman parte de la biodiversidad nacional, a través de la implantación del "Programa Educativo "Ave Aventura" dentro del MHNP.

Metodología: Utilizando la Metodología Observacional por medio de la experimentación de sus diferentes talleres con actividades articuladas con el programa de estudios, se llega una Metodología Comparativa con el Museo de Historia Natural e Indigenista, para adaptarlo según el contexto paraguayo, en la que se toma como modelo una de las salas que cuenta con la colección de Aves del Paraguay, en la que se toma una de las colecciones El pájaro campana

1. Universidad Autónoma de Madrid, UAM. Facultad de Formación del Profesorado.

E-mail: franjavi.1949@gmail.com

DOI: 10.26885/rcei.foro.2018.52 
que servirá como gancho para conocer las demás especies nativas.

Conclusión: La importancia de promover actividades extracurriculares que contribuyan a mejorar la calidad educativa. Paraguay cuenta con otros Museos y espacios donde se podría plantear la implantación de esta propuesta o de otras con el mismo carácter pedagógico, como se menciona en otros apartados este sería el primer paso para desarrollar futuros programas que apunten a responder a necesidades de los niveles des sistema educativo paraguayo.

Palabras clave: programa educativo, taller, museos, sistema educativo.

\section{Referencias}

García, J., González, M., Velázquez, B. (2001). Introducción a la investigación en educación. Madrid: UNED.

ICOM. (12 de Julio de 2017). ICOM. Recuperado de http://icom.museum/ la-vision/definicion-del-museo/L/1/

JBZA. (20 de Julio de 2017). Jardín Botánico y Zoológico de Asunción. Recuperado de http://www.jbza.org/v3/

Mateo, J., \& Martínez, F. (2008). Medición y evaluación educativa. Madrid: La Muralla.

Ministerio de Educación y Ciencias. (sf). $1^{\circ}$ grado. Recuperado de https://www. mec.gov.py/cms_v2/adjuntos/4932 